\title{
Identification and characterization of Flavobacteriaceae from farmed Oreochromis niloticus and Clarius gariepinus in Uganda.
}

\author{
AMONO RACHEAL ${ }^{1}$, CHRISTOPHER J. KASANGA ${ }^{1, \boldsymbol{v}}$, DENIS K. BYARUGABA ${ }^{2}$ \\ ${ }^{1}$ College of Veterinary Medicine and Biomedical Sciences, Sokoine University of Agriculture. Tanzania. "email: christopher.kasanga@ sacids.org, \\ chrisskasa@gmail.com \\ ${ }^{2}$ College of Veterinary Medicine, Animal Resource and Biosecurity, Makerere University. Kampala, Uganda
}

Manuscript received: 20 March 2018. Revision accepted: 29 June 2018.

\begin{abstract}
Racheal A, Kasanga CJ, Byarugaba DK. 2018. Identification and characterization of Flavobacteriaceae from farmed Oreochromis niloticusand Clarius garieoinus. Bonorowo Wetlands 8: 42-50. Bacteria under the family Flavobacteriaceae (also called Flavobacteria) are important pathogens of fish, people, many other animals, and plants in this study. In this study, Flavobacteria from Nile tilapia (Oreochromis niloticus) and African catfish (Clarius gariepinus) were identified and characterized from the selected farms in Uganda. Gill and skin swabs were obtained from 119 fish from 19 farms and were dissected aseptically to sample internal organs. The samples were inoculated onto Shieh media and incubated at $25^{\circ} \mathrm{C}$ for 48 hours. The suspected isolates were identified by colon characteristics, conventional biochemical tests, and API 20 NE kits. The isolates were grouped into eight based on characteristic colon similarity. One group selected one isolate for 16S rRNA gene sequencing and identified using the EZbiocloud.net ID software. Phylogenetic analysis of selected isolates was performed using the 16S rRNA gene sequences in BioEdit and MEGA 7.0.2 software. Based on extrapolation of sequence analysis of the selected isolates, out of the 86 isolates, Myroides marinus was the most predominant species taking up 4 of the 8 groups (60 isolates) in 13 farms. The rest of the groups comprised; Acinetobacter pitti, one group (6 isolates) in 6 farms, Chryseobacterium gambrini 2 groups ( 3 isolates) in 3 farms, and one isolate was unidentified in 3 farms. However, a total of 16 isolates did not grow on subculturing. Phylogenetic analysis indicated that M. marinus isolates grouped with other M. marinus isolates from gene bank with significant intra-species diversity, observed with $C$. gambrini isolates. All the sampled farms had at least one isolate of a Flavobacterium from Tilapia and/or Catfish. Pathogenicity studies should be conducted on the isolates to establish their importance as fish pathogens and transmission dynamics so that an appropriate control measure can be recommended.
\end{abstract}

Keywords: Clarius garieoinus, Flavobacteriaceae, Oreochromis niloticus

\section{INTRODUCTION}

Agriculture is the backbone of Uganda`s economy, with aquaculture as one of the major enterprises highly growing, yet still with enormous potential for production (NDP11 2015/2016-2019/20). However, an increase in aquaculture is accompanied by an increased risk of diseases. Earlier it was observed during research that over $70 \%$ of fish farms in central and western Uganda sampled with farmed tilapia and catfish had a high incidence of four bacterial pathogens, including Pseudomonas sp., Aeromonas sp., Vibrio sp., and $F$. columnare of family Flavobacteriaceae (Walakira et al. 2014).

All over the world, there are numerous species of Flavobacteriaceae having a ruinous effect on the wild and farmed fish stocks. Flavobacterial disease eruptions are infamously challenging to avert and control, even though much research has been carried out for nearly 100 years. They are known for their great economic and ecological effects (Wagner et al. 2002; Welker et al. 2005). Fish that recover from some Flavobacterial diseases remain carriers and shed the bacteria into the environment, making them more dangerous in aquaculture (Welker et al. 2005).
Phylogenetic analysis of Flavobacterial fish pathogens is critical for the appropriate control of infections caused, especially given that Uhas a high growth rate in aquaculture (MAAIF 2004). Information about Flavobacterial diseases in Uganda is not well documented, but several undocumented cases (unpublished, NAFIRI, Kajansi). The occurrence of diseases caused by Flavobacterial pathogens in countries with high aquaculture production like America, Europe, and Asia (Shotts and Starliper 1999; Farmer 2004; Zamora et al. 2012 a,b; Loch and Fasial 2014), could be one of the indications that Uganda will at one time face the same problem. Therefore, it is important to proactively study species prevalent in the country and further studies on their pathogenicity. It may be possible to develop and implement appropriate control measures such as vaccination using tailored vaccines.

Specific objectives are to determine the occurrence of Flavobacteriaceae in Oreochromis niloticus and Clarius gariepinus in the selected farms in Uganda and to determine the molecular characteristics of Flavobacteriaceae isolates from Oreochromis niloticus and Clarius gariepinus in the selected farms in Uganda, using the 16S rRNA gene. 


\section{MATERIAL AND METHODS}

\section{The study area}

The study was conducted on selected farms in the districts of Wakiso, Kampala, Lira, Arua, Nebbi, and Kole (Kole is a new district that has just been formed from Lira district) (Figure 1).

\section{Study design}

This was a cross-sectional study to isolate and identify Flavobacteriaceae isolates from African catfish and Nile tilapia in selected farms in Uganda. Bacteria were isolated from fish collected between October 2016 and March 2017. These were identified as Flavobacteria based on growth colony characteristics (color, elevation, margin texture, colony consistency), biochemical tests, and sequencing of the $16 \mathrm{~S}$ rRNA gene.

\section{Sampling}

Convenience and purposive sampling techniques were used in this study. Purposive sampling was done based on disease history, presence of disease, availability of farms, and accessibility to the farms. A total of 119 fish were collected from 19 farms. Live fish in water troughs were transported to the College of Veterinary Medicine Animal Resources and Biosecurity (COVAB) Central Diagnostic Laboratory (CDL), Makerere University, Kampala.

\section{Isolation of bacteria under family Flavobacteriaceae}

Samples of internal organs were taken aseptically, including kidneys, liver, and spleen. These were homogenized by cutting into smaller pieces using a sterile surgical blade and then inoculated into Shieh broth. Swabs were also obtained from skin, lesions, and gills using a sterile swab stick and inoculated on Shieh 's agar. The samples were incubated at 25 for 48 hours. Liver, kidney, and spleen were pooled into Shieh broth for 24 hours before culturing on Shieh agar supplemented with tobramycin at a concentration of $0.001 \mathrm{~g} / \mathrm{L}$.

\section{Morphological identification of Flavobacteria colonies}

The phenotypic characterization of the isolates was designed based on colony morphology, Gram staining, standard biochemical tests, and their consistency. All yellow bacterial colonies were considered for the study. Shieh agar and Shieh broth were made for bacterial growth as in the table in appendix 1. Cellular morphology was determined by Gram staining and viewed under a microscope whereby gram-negative rods were considered (magnification, x 100).

\section{Identification of Flavobacteria by biochemical tests}

Colonies were grown in peptone water for 48 hours, and motility was determined under a light microscope (magnification, x 100). Other biochemical tests included; the presence of flexirubin type pigments using $1 \% \mathrm{KOH}$, cytochrome oxidase, catalase, TSI (Triple Sugar Iron Agar) tests (Sebastião et al. 2010). API 20NE test kits from Biomerieurix were also used at Makerere University and the Norwegian University of Life Sciences (NMBU) as screening tests to identify isolates before further sequencing.

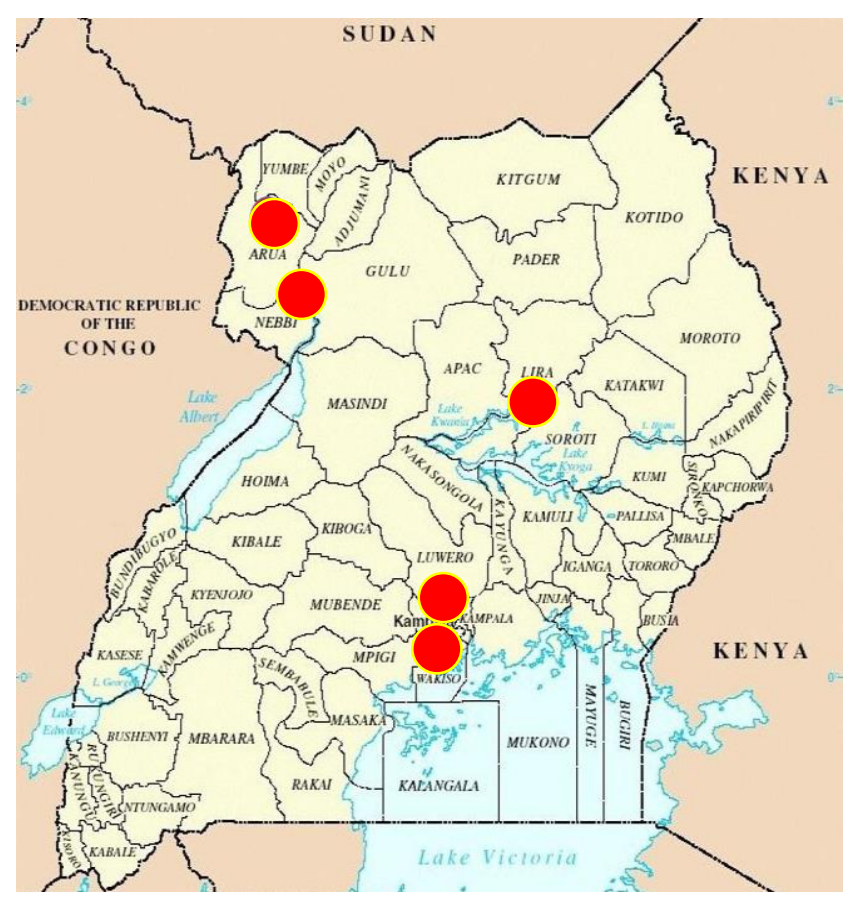

Figure 1. Map of Uganda and study area

\section{Molecular identification of Flavobacteria}

The isolates were preserved on Shieh agar slants and transported at room temperature to the microbiology laboratory at the Norwegian University of Life Sciences. The bacteria were sub-cultured on agar (BHI agar media was used from DIFCO Laboratories, and Merck KGaA Germany and the suspected Flavobacteriaceae colonies were divided into eight groups based on colony morphology similarity (based on colony color, size, elevation, margin) and one colony per group was selected for sequencing.

\section{DNA extraction for Flavobacteria sequencing}

Genomic DNA was extracted from the 8 selected isolates at the Gen-lab NMBU, where further molecular analysis was performed. Genomic DNA isolation was done using a QIAamp DNA mini kit (Qiagen). The manufacturer`s protocol was followed as stated in appendix 2 , and all spin steps used a benchtop Mini spin centrifuge.

\section{PCR process for the extracted DNA}

The 16S rRNA genes were amplified by PCR using universal bacteria primers $27 \mathrm{f}$ (5'AGAGTTTGATCCTGGCTCAG-3 and 1492R (5'GGTTACCTTGTTACGACTT-3'). Each PCR reaction was performed in a final volume of $25 \mu \mathrm{L}$ containing: $2.5 \mu \mathrm{L}$ of $10 \mathrm{X}$ reaction buffer (50MM, 75MM Tris-HCL pH 9.0), $\left.2 \mathrm{MM} \quad \mathrm{MgCl}_{2}, \quad 20 \mathrm{MM} \quad\left(\mathrm{NH}_{4}\right)_{2} \mathrm{SO}_{4}\right), \quad 0.5 \mu \mathrm{L} . \quad 10 \mathrm{MM}$ deoxyribonucleotide mix, $0.2 \mu \mathrm{L}$ of DNA template, and $16.8 \mu \mathrm{L}$ of sterile ultrapure water. PCR reactions were performed by icycle (from Bio-Rad) under the following conditions: Initial denaturation at $94{ }^{\circ} \mathrm{C}$ for $3 \mathrm{mins}$, followed by 30 cycles of amplification as follows; denaturation at $94^{\circ} \mathrm{C}$ for the $30 \mathrm{~s}$, annealing at $56^{\circ} \mathrm{C}$ for $30 \mathrm{~s}$ and extension at $72^{\circ} \mathrm{C}$ for 2 mins, followed by a final 
extension step at $72^{\circ} \mathrm{C}$ for 5 minutes and left to stand at $4^{\circ} \mathrm{C}$ until analysis.

\section{Electrophoresis}

The PCR products were then run on $1 \%$ ultra-pure agarose (Invitrogen, Thermo Fisher Scientific) using Power Pac 300 (BioRad) at 100Volts for 60 minutes with Gene Ruler $^{\mathrm{TM}} 1 \mathrm{~kb}$ Ladder. The gels prestained with syberSafe (source) were visualized using Safe Imager ${ }^{\mathrm{TM}}$ (Invitrogen), and bands of interest were excised with a scalpel blade. Gel pictures were captured using ChemiDoc ${ }^{\mathrm{TM}}$ XRS Molecular imager (Bio-Rad).

\section{Purification of the PCR products and sequencing}

The PCR products were purified using a QIAquick Gel Extraction kit (Quiagen) following the manufacturer's instructions as stated in appendix 2. The Purified PCR was quantified, and quality was checked using Nanodrop ND1000 Spectrophotometer (Thermo Fisher Scientific inc.) and sent for sequencing by sanger sequencing technology and technique at GATC Biotech, Germany, using the same primers as those used for PCR.

\section{Data analysis}

Data were summarized and stored in Microsoft Excel version 10. BLAST searches were done online to get similar sequences from the NCBI website's gene banks. The obtained sequences from isolates in this study were edited using bio edit and aligned with those retrieved from gene banks using the Claustal $W$ algorithm in MEGA version 7.0 software. The alignments were used to construct a phylogenetic tree using the Neighbor-Joining method using the Kimura-2-parameter model. Identification of the sequences was also made using EZBiocloud.net ID software online.

\section{RESULTS AND DISCUSSION}

\section{Biodata for the sampled farms}

Data of the sampled farms can be seen in Table 1.

\section{Symptoms were encountered in the fish samples.}

Both symptomatic and asymptomatic fish were sampled; some of the lesions encountered in the symptomatic fish included: hemorrhages on the skin, fins, barbells, yellow skin, skin erosions, swollen belly, eroded tail fin, pale liver. Figure 2 shows some of the lesions.

Table 1. Biodata of the selected farms

\begin{tabular}{|c|c|c|c|c|c|}
\hline Status of farmer & No. of units & Species of fish & Sources of water & History of disease & Culture systems \\
\hline 16 small scale farms & $\begin{array}{l}2-5 \text { units for } \\
\text { small scale }\end{array}$ & $\begin{array}{l}\text { Koi carp } \\
\text { Silver carp }\end{array}$ & $\begin{array}{l}\text { Lake } \\
\text { River } \\
\text { Underground } \\
\text { Streams }\end{array}$ & $\begin{array}{l}5 \text { farms }(26.31 \%) \\
\text { with disease } \\
\text { outbreak/ history }\end{array}$ & $\begin{array}{l}13 \text { farms with only earthen } \\
\text { ponds } \\
3 \text { farms with only cages }\end{array}$ \\
\hline 3 large scale farms & $\begin{array}{l}\text { over } 20 \text { units for } \\
\text { large scale }\end{array}$ & $\begin{array}{l}\text { African catfish } \\
\text { Tilapia }\end{array}$ & & & $\begin{array}{l}2 \text { farms with tanks and ponds } \\
1 \text { farm with tanks only }\end{array}$ \\
\hline
\end{tabular}

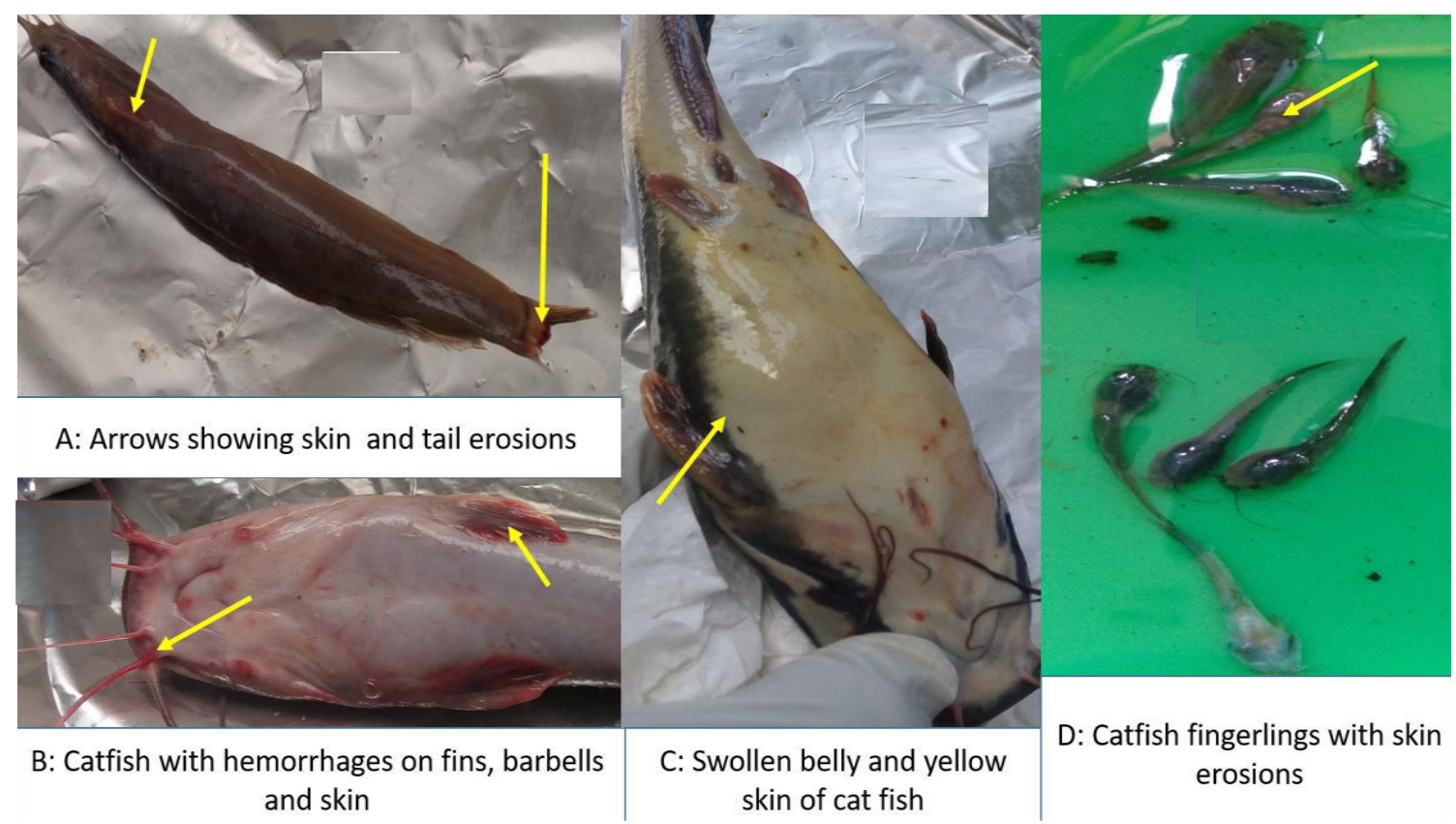

Figure 2. Lesions encountered on catfish 


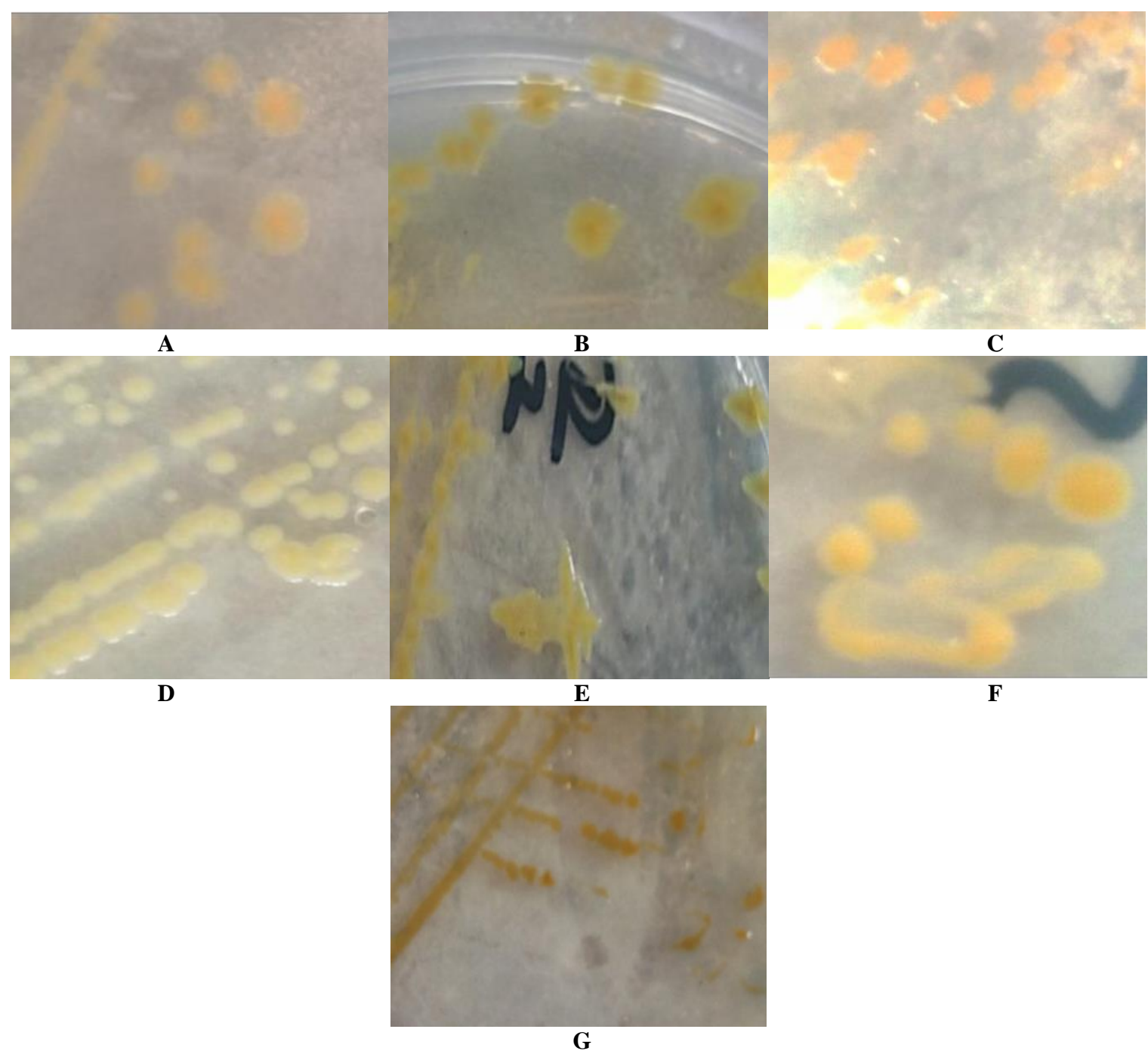

Figure 3. Colony characteristics of the study isolates. A. Isolate 1. Soft, sticky, bright yellow, flat, large size, smooth; B. Isolate 2. Soft, large, yellow, flat, gelatinous; C. Isolate 3. Yellow, medium size, flat, glistening; D. Isolate 5. Pale yellow, round, flat, medium size, shinny; E. Isolate 6. Soft, sticky, yellow, flat, medium size, irregular; F. Isolate 7. Large, yellow, round, smooth, flat, soft; G. Isolate 8. Small, orange, round, raised

\section{Culture and isolation of flavobacteria}

Culturing the pooled organs in Shieh broth followed by streaking the broth on Shieh agar always gave fewer types of colonies (sometimes only one) per sample than direct streaking of the gill and skin swabs on agar. A total of 86 isolates were obtained from the 119-fish sampled, with colonies ranging from pale yellow, bright yellow, deep yellow to orange and had a fruity odor and varying sizes ranging from small to large. The 86 isolates were grouped into 8 groups based on colony growth characteristic similarities (color, elevation, margin texture, size of colonies), and one representative isolate from each group was considered for sequencing.

\section{Colony characteristics}

A total of 86 isolates were got with colonies ranging from pale yellow, bright yellow, deep yellow to orange and had a fruity odor and varying sizes ranging from small to large. These were grouped into 8 and one colonies per group selected. Figure 3 shows some of the chosen colonies for sequencing but missing the colony for isolate 4 .

\section{Biochemical test results}

Biochemical test results for the sequenced isolates

The biochemical test results are summarized in Table 2. Some colonies produced $\mathrm{H}_{2} \mathrm{~S}$, but after storage and subculturing and their TSI test did not give off $\mathrm{H}_{2} \mathrm{~S}$.

\section{General biochemical test results for the groups}

Table 3 summarizes the biochemical test results of the isolates in the groups from which the sequenced isolates were obtained. Some groups had only one isolate (i.e., groups 6 and 5), while one group had two isolates (group 8 ). The group from which isolate 8 was got had two isolates, but biochemical tests results of the other isolates are missing. Isolate 8 thus has a star in the table to indicate missing results. 


\section{API test results}

The API test results shown in Table 4 were for some selected isolates, most of which were not sequenced directly or did not regrow on subculturing thus. Some isolates tested using the API 20NE kits gave codes that had unacceptable profiles and were not identified, as shown in Table 4.

Table 2. Biochemical test results of the sequenced isolates

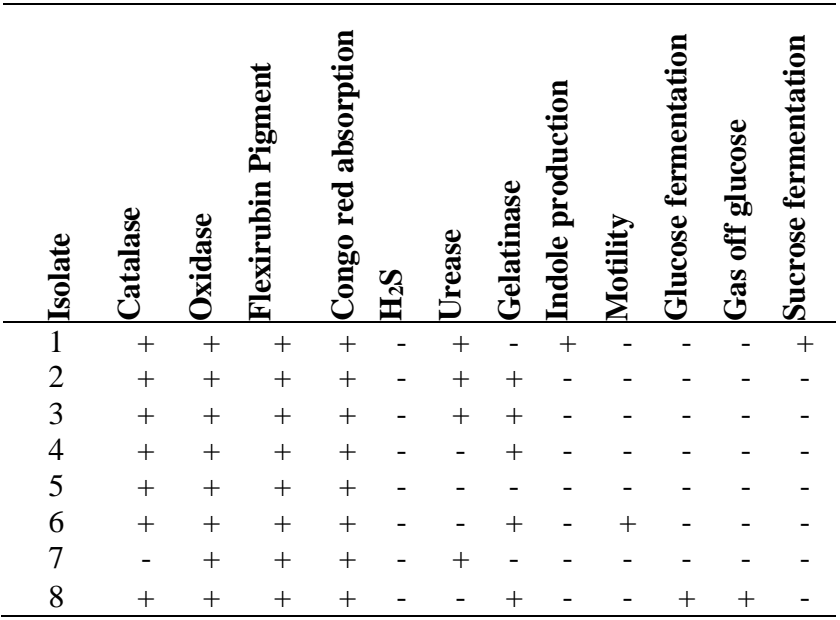

Table 4. API 20NE results

\begin{tabular}{cclc}
\hline Isolate & Group & \multicolumn{1}{c}{ Identification } & $\begin{array}{c}\text { Percentage } \\
\text { Identification }\end{array}$ \\
\hline A & NR & Unacceptable profile & N/A \\
B & NR & Unacceptable profile & N/A \\
C & NR & Unacceptable profile & N/A \\
D & NR & C. indolgenes & 90.6 \\
E & NR & Acinetobacter sp. & 60 \\
F & NR & C. indolgenes & 99.9 \\
G & 1 & Myroides sp. & 64 \\
H & 1 & Weeksiela sp. & 37 \\
1 & 1 & Myroides sp. & 64 \\
I & 3 & C. indolgenes & 49 \\
\hline
\end{tabular}

Note: NR- Not represented in the groupings since did not grow on sub-culturing N/A- Not applicable.
Comparison of conventional and API 20NE biochemical test results

The biochemical tests compared between the conventional laboratory method and the API 20NE kits were glucose fermentation, presence of urease activity (URE), gelatin hydrolysis (GEL) by gelatinase, oxidase activity (OX), and indole production (TRP). There were minimal differences in the test results observed between the two methods (not more than two tests out of the five tests per isolate), as observed in Table 5.

\section{Electrophoresis results}

Figure 4 shows the electrophoresis results with the bands of sizes of approximately 1500bp (indicated by an arrow) obtained using universal bacterial primers $27 \mathrm{~F}$ and 1492R.

Table 5. Comparison of API 20NE and conventional tube test results for selected isolates

\begin{tabular}{ccccccc}
\hline Isolate & Test method & GLU & URE & GEL & OX & TRP \\
\hline $\mathrm{A}$ & API & - & + & + & + & + \\
& Conventional & - & - & + & + & + \\
$\mathrm{B}$ & API & + & - & + & + & + \\
& Conventional & - & + & + & + & + \\
3 & API & - & + & + & + & - \\
& Conventional & Missing & + & + & + & - \\
$\mathrm{C}$ & API & - & - & + & + & + \\
& Conventional & - & - & - & + & + \\
$\mathrm{D}$ & API & - & - & + & - & + \\
& Conventional & - & - & + & + & + \\
$\mathrm{E}$ & API & - & + & + & - & - \\
& Conventional & - & + & Missing & + & + \\
$\mathrm{F}$ & API & - & + & + & - & + \\
& Conventional & - & + & + & + & + \\
1 & API & - & + & + & - & - \\
& Conventional & - & + & + & + & + \\
$\mathrm{G}$ & API & - & + & + & - & - \\
& Conventional & - & + & + & + & - \\
$\mathrm{H}$ & API & - & - & + & - & - \\
& Conventional & - & + & + & + & - \\
$\mathrm{I}$ & API & - & + & + & - & - \\
& Conventional & - & + & + & + & - \\
\hline
\end{tabular}

Table 3. General biochemical test results of the groups

\begin{tabular}{|c|c|c|c|c|c|c|c|}
\hline $\begin{array}{l}\text { Representative sequenced } \\
\text { isolate }\end{array}$ & $\mathbf{1}$ & 2 & 3 & 4 & 5 & 6 & $8 *$ \\
\hline No. of isolates in the group & 14 & 3 & 30 & 13 & 1 & 1 & 2 \\
\hline Flexirubin & $92.9(+)$ & $100(+)$ & $93.3(+)$ & $76.2(+)$ & $(+)$ & $(+)$ & $(+)$ \\
\hline Catalase & $100(+)$ & $100(+)$ & $96.7(+)$ & $100(+)$ & $(+)$ & $(+)$ & $(+)$ \\
\hline Oxidase & $85.7(+)$ & $66.7(-)$ & $86.7(+)$ & $70.0(+)$ & $(+)$ & $(+)$ & $(+)$ \\
\hline Congo red & $100(+)$ & $100(+)$ & $93.3(+)$ & $70.0(+)$ & $(+)$ & $(+)$ & $(+)$ \\
\hline Urease & $100(+)$ & $100(+)$ & $60.0(+)$ & $76.9(+)$ & $(-)$ & $(-)$ & $(-)$ \\
\hline TSI & $92.9(-)$ & $100(-)$ & $83.3(-)$ & $84.6(-)$ & $(-)$ & $(-)$ & $(+)$ \\
\hline $\mathrm{H} 2 \mathrm{~S}$ & $100(-)$ & $100(-)$ & $96.7(+)$ & $100(-)$ & $(-)$ & $(-)$ & $(-)$ \\
\hline Gliding motility & $92.9(-)$ & $66.7(-)$ & $93.3(-)$ & $84.6(-)$ & $(+)$ & $(-)$ & $(-)$ \\
\hline Indole production & $71.4(-)$ & $100(-)$ & $70.0(-)$ & $53.8(-)$ & $(-)$ & $(-)$ & $(-)$ \\
\hline Gelatin hydrolysis & $50.0(+)$ & $100(+)$ & $73.3(+)$ & $92.3(+)$ & $(+)$ & $(+)$ & $(+)$ \\
\hline Glucose fermentation & $92.9(-)$ & $100(-)$ & $96.7(-)$ & $92.3(-)$ & $(-)$ & $(-)$ & $(+)$ \\
\hline Gas from glucose fermentation & $100(-)$ & $100(-)$ & $100(-)$ & $92.3(-)$ & $(-)$ & $(-)$ & $(+)$ \\
\hline Sucrose fermentation & $92.9(-)$ & $100(-)$ & $93.3(-)$ & $92.3(-)$ & $(-)$ & $(-)$ & $(-)$ \\
\hline
\end{tabular}




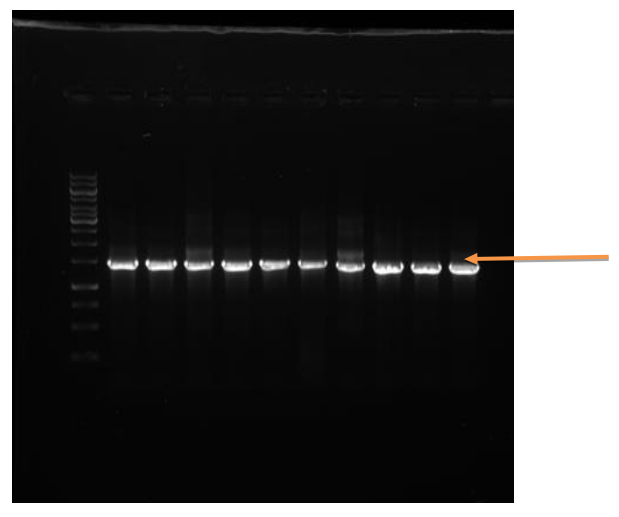

Figure 4. Electrophoresis results for the 16S rRNA gene

\section{Identification and occurrence of the isolates}

Identification of isolates using Ezbiocloud.net

The most familiar isolated species was M. marinus. The closest strain to the isolates was M. marinus JS 08 (GQ857652) at a percentage similarity of 99.0 to $99.79 \%$ (for the different group's isolates) using Ezbioclod.net. These were isolated on 15 farms out of the 19 sampled farms. The least common species isolated were those closely similar to $M$. odoramitimus, with closet strain as $M$. odoratimimus CCUG 39352 at percentage similarity of 86.7\% and Chryseobacterium gambrini with closest strain as C. gambrini DSM 18014 at a percentage similarity of 98.37 to $97.82 \%$ (for the different selected isolates) using Ezbiocloud.net.

Table 6 shows the identification of the isolates, the health status, species of fish (Oreochromis niloticus (O.n) or Clariaus gariepinus (C.g), and site of fish from which they were isolated, culture system and water source of the farms from which the isolates were obtained.

\section{Identification of the 86 isolates}

Figure 5 shows the composition of the isolates based on the extrapolation of the results of the sequenced isolates.

\section{Phylogenetic analysis \\ Occurrence of flavobacteria on the farms}

Of the 19 sampled farms, Myroides marinus was the commonest while the unidentified isolate was the least common. The isolates were distributed on the farms, as summarized in Figure 6.

Key: The Neighbor-Joining method implied the evolutionary history (Saitou and Nei 1987): The optimal tree showed the sum of branch length $=0.51734957$. The percentage of replicate trees in which the associated taxa clustered together in the bootstrap test (1000 replicates) are shown next to the branches (Felsenstein 1985). The evolutionary distances were computed using the Kimura 2parameter method (Kimura 1980) and are in the units of the number of base substitutions per site. The analysis involved 16 nucleotide sequences. All positions containing gaps and missing data were eliminated. There was a total of 989 positions in the final dataset. Evolutionary analyses were conducted in MEGA7 (Kumar et al. 2016).

The isolates 1,2,3, and 4 were grouped with the other M. marinus isolates obtained from the gene bank. Isolate 2 and 3 were more closely related to each other, and the reference strain M. marinus JS 08 compared to isolates 1 and 4. Isolate 4 was furthest from the reference strain of all the M. marinus isolates. Therefore, there is diversity in the phylogenetic relatedness between isolates $1,2,3$ and 4 . Isolate 6 did not cluster with any of the other isolates. Isolates 8 and 5 were grouped with the other $C$. gambrini isolates obtained from the gene bank. Isolate 5 was more closely related to the reference strain than isolate 8 .

Table 6. Identification of isolates and their occurrence in fish

\begin{tabular}{llllll}
\hline & & & & \\
& & &
\end{tabular}




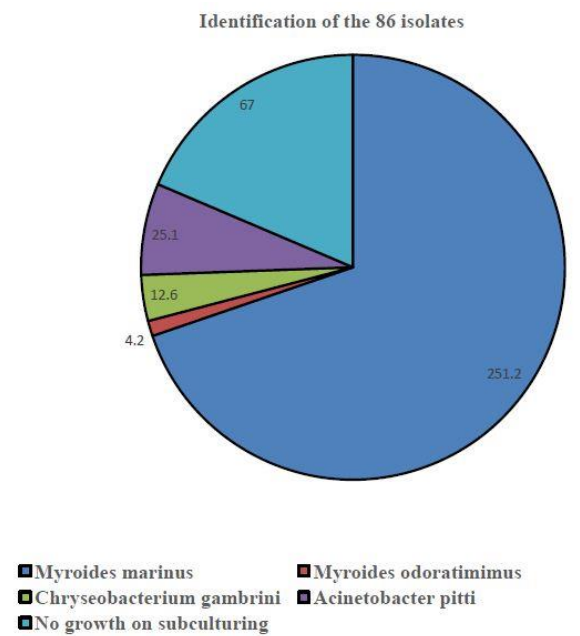

Figure 5. Identification based on the extrapolation of results of sequenced isolates

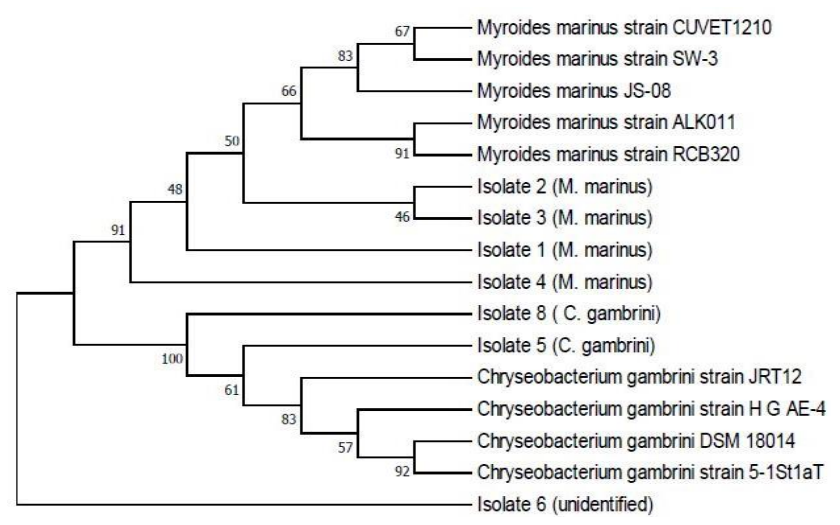

Figure 7. Phylogenetic relatedness of the isolates based on the $16 \mathrm{~S}$ rRNA gene

The graphical views showing a comparison of the isolates to their reference strains are shown in appendix 4 . The isolates 1,2,3, and 4 differed from the reference strain M. marinus JS 08 GQ857652 at regions between 221 and 223, 591, but most especially between 1097 and 1302 . Isolate 4 had the greatest differences of the four isolates. The isolates 5 and 8 differed from the reference strain $C$. gambrini JGI1096583 in the regions between 270 and 277, 978 and 996 . Isolate 8 had more nucleotide differences to the reference strain than isolate 5 .

\section{Discussion}

Flavobacteria are significant fish pathogens of importance in aquaculture worldwide (Wakabayashi et al. 1989; Shotts and Starliper 1999; Nematollahi et al. 2003; Bernardet et al. 2006; Starliper 2011; Loch and Fasial 2015). Previous studies in Uganda by Walakira et al. (2014) indicated that $F$. columnare had a high prevalence in the selected farms in central and western Uganda. This study determined the occurrence of Flavobacteria in fish farms and their molecular characterization to understand the Flavobacterial diseases better.

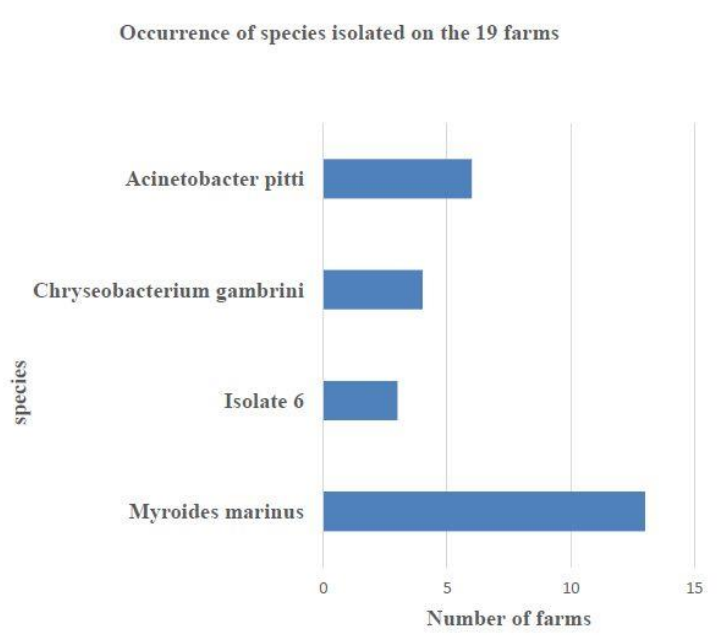

Figure 6. Occurrence of isolates on the selected farms

In this study, all the selected farms had at least one bacterium from the family Flavobacteriacea isolated, and some had more than one colony type of the isolates. Some of these Flavobacteria, like the Myroides species, can cause disease in laboratory experiments but have not yet been reported to cause disease in the natural (Chinnarajan et al., 2015). Sixteen isolates did not grow on subculturing and thus were not represented in the sequencing of the selected isolates in this study.

Many genera have emerging pathogens that include Chryseobacterium, Tenacibacterium, Ornithobacterium, Elizabethkingia, and these include pathogens of reptiles, humans, birds, mammals, and fish health importance (Loch and Fasial 2015).

Seven out of the eight selected representative isolates in this study were closely related to the family Flavobacteriaceae, grouped under the genera Myroides and Chryseobacterium as shown by the phylogenetic tree in Figure 7. These are some of the genera with the most familiar species that have been reported to be associated with sick fish and even causing disease in fish (Loch and Fasial 2015).

Sixteen out of the 19 farms in this study were smallscale farms, some getting water sources from the wild. Previous studies of problems facing small-scale farmers in Asia, Particularly Thailand, ranked disease second to lack of funds (Chinabut et al. 2002).

Eight groups of the isolates were made during the present study based on similarity in the morphology of the colony, and only one per group was sequenced. This was due to limited resources, but it would have been better if each isolate had been sequenced and identified individually because there is a possibility that different species or strains were grouped. Some isolates identified as the same species were morphologically different (Figure 3) and had some differences in their biochemical reactions for the tests that were carried out (Table 2), for example, isolates 1, 3, 2 , and 4 that still turned out to the group with the reference strain Myroides marinus JS 08 (bootstrap values above $60 \%$ ) and were identified as Myroides marinus (Table 6). 
The colony morphological and biochemical differences could be due to the strains that were not well studied here. The fact that some of the isolates had a phylogenetic relationship and yet were found in different farms in different parts of the country could indicate a similar source. Most of the sampled farms had previously received fingerlings from Kajansi through a government project to support fish farmers in Uganda, thus could be a common source. Isolate 6 was not closely related to any of the other isolates in this study, not even to $M$. odoratimimus, the closest possible species. Although the closest strain was $M$. Odoratimimus, the percentage similarity of $86.7 \%$ is low, and thus the isolate is a bacterium probably not under the family Flavobacteriaceae.

Isolate 7 , although with the colony and biochemical characteristics similar to Flavobacteria, was identified as Acinetobacter pitti using EZtaxon ID software. The biochemical tests of many colonies in this study tentatively suggested $F$. columnare but were ruled out by the API kits and 16S rRNA gene sequencing. There were differences in the biochemical characteristics of isolates between and within the groups formed, as shown in Tables 3 and 4. This could be because of differences in species or strains among the isolates in each group. The colony characteristics (color, size, elevation colony margins) similarity used to group the isolates are insufficient to differentiate the bacteria species or strains of Flavobacteria. For example, isolates 1, 2, and 3 were all identified as M. marinus but have different colony growth characteristics, as shown in Figure 3. Graphical views in appendix 3 revealed differences in their nucleotides between the isolates 1, 2, 3, and 4 and thus could be due to differences in the strains.

Similarly, isolates 5 and 8 were both identified as $C$. gambrini but had differences in biochemical test results; for example, isolate 8 fermented glucose, produced acid on TSI and did not have gliding motility while isolate 5 did not ferment glucose, no acid production in TSI and had gliding motility.

API 20NE kits, when used in this study, could rule out $F$. columnare even though morphological and biochemical tests suggested otherwise. The comparison to identification by API kits and 16s RNA gene sequencing was not well studied here. However, both API kits and 16S RNA gene sequencing did not identify any major Flavobacteria. The API test results for isolates G and I at $64 \%$ identity gave a correct genus identification even though the percentage identity was still considered low. For isolates $\mathrm{H}$ and I, the percentage identification was below average; the identification was incorrect compared to sequence identification. The API results in this study generally had low percentage identities and were not reliable. Adley and Saieb (2005) compared biomeriueux API 20NE and Remel RapiD NF Plus in the identification systems of type strains of Ralstonia picketti. Only 29 out of 48 isolates were identified, and the API 20NE was considered inconsistent. However, the use of API kits (API NE and API ZYM) in a study by Farmer proved to be useful in identifying $F$. columnare (Farmer 2004). When used in this study, API NE kits could rule out $F$. columnare even though colony morphology on Shieh agar and biochemical tests suggested otherwise. The identification by API kits and 16s RNA gene sequencing was not well studied here. However, both API kits and 16S RNA gene sequencing did not identify any major Flavobacteria. There were minimal differences in the five test results observed between the two methods (not more than two tests out of the five tests per isolate), as observed in Table 5. However, the number of samples tested and the number of the biochemical tests compared were too small to be reliable for a consequence.

Distinct findings were furnished in this study compared to those of the previous studies done in Uganda, which indicated a high incidence of $F$. columnare (Walakira et al. 2014). However, in this study, there is an increased occurrence of bacteria under the family Flavobacteriaceae except for $F$. columnare. There is a possibility that the presumed $F$. columnare in Walakira et al.'s (2014) study could have been different species under the o genera of the family Flavobacteriaceae. The physiological, morphological, and biochemical analysis of the suspected $F$. columnare colonies in that study probably led to a misdiagnosis. The diagnosis of lesser-known Flavobacteria in fish is difficult and laborious (considering $F$. columnare, $F$. branchiophilum, and $F$. psychrophillum as the major Flavobacteria (Loch and Fasial 2015). There are few diagnostic reagents specific for the lesser-known fishassociated Flavobacteria organisms. Diagnosis is further made more difficult because Flavobacteria are being discovered at a high rate and their classifications keep on changing (Bernardet et al. 1996; Qu et al. 2009; Lee et al. 2010, Yoon et al. 2011; Loch and Fasial 2015). Varga et al. (2016) similarly surveyed the incidence of $F$. columnare in wild and cultured freshwater fish species in Hungary. A total of twenty-five isolates from wild and cultivated freshwater fishes were identified as F. columnare using specific PCR. However, both the fragment lengths and the results of PCR-RFLP genotyping with BsuRI (HaeIII) and RsaI restriction enzymes were not convincing enough regarding $F$. columnare classification. Sequencing the $16 \mathrm{~S}$ ribosomal RNA gene revealed that 23 isolates belonged to the species $F$. johnsoniae, and two represented Chryseobacterium spp. Thus showing that misidentification of Flavobacteria is easily possible (Varga et al. 2016).

The commonest of the Flavobacteria isolated in the selected farms in this study was $M$. marinus, as indicated in Table 3 and Figures 2 and 3. The isolates were obtained from both symptomatic and asymptomatic fish, for example, isolates (Table 6). Clinical signs in the symptomatic fish included skin erosions, hemorrhages, yellowing of the skin, swollen belly, and fin erosions, as shown in Figure 2. Some of the isolates from symptomatic fish with skin erosions, such as isolates 1 and 8, were recovered from catfish fingerlings (Clariaus gariepinus) that were reportedly experiencing abnormal mortalities for a week. Isolate 8 was identified as C. gambrini. Loch, in his study, stated that Flavobacterium sp. and Chryseobacterium spp. were an extensive cause of fingerling and fry mortalities in Michigan (Loch 2014). However, this case requires further experimental studies to tell if the isolates were the causative agents for the skin erosions and death of the catfish fingerlings since there is a possibility of mixed infection. 
A previous study by Loch has shown different Flavobacteria species being isolated from both symptomatic (with hemorrhages, skin and fin erosions, gill necrosis) and asymptomatic fish, some of which were just emerging fish pathogens (Loch 2014). Other than the threemain fish disease-causing Flavobacteria, other emerging Flavobacteria have also been found to cause hemorrhages erosions on the skin and fins (Loch and Fasial 2015). The Original Flavobacteria known to be causing fish health issues were the $F$. columnare, $F$. branchiophilum, $F$. psychrophilum, but there are many other Flavobacteriacea causing disease in fish. The newly identified Flavobacteria vary in the degree of virulence, for example, C. aahli sp. Nov. was found to be mildly pathogenic to fish under laboratory conditions, while $F$. spartani $s p$. nov. was rather more pathogenic (Loch 2014). Thus, it is important to study the pathogenicity of emerging Flavobacteria.

Some farmers reported poor growth of fish. This could be due to many other factors that could include but are not limited to poor management, genetic factors, reproduction in Tilapia, and diseases. However, Flavobacteriosis is one of the diseases that could lead to poor growth of fish that survive the infection. Acute Flavobacteriosis was reported to contribute to poor growth in fish that survive which sometimes present with spinal abnormalities (Austin and Austin 2007).

\section{Conclusion}

All the sampled farms had at least one isolate of Flavobacterium from Tilapia and/ or Catfish. Myroides marinus was common in the selected farms in this study isolated on 13 farms which are $68.4 \%$ of the 19 farms. However, C. gambrini (on 4 farms) and the unidentified isolate 6 (on 3 farms) were not very common in the selected farms. None of the major Flavobacteria ( $F$. columnare, F. branchiophilum, and $F$. psychrophillum) was identified in this study. The routinely used biochemical and morphological growth characteristics were insufficient to identify Flavobacteria. Phylogenetic analysis indicated that M. marinus isolates grouped with other M. marinus isolates from the gene bank. Although intra-species diversity was observed, a similar situation was observed with $C$. gambrini isolates.

\section{REFFERENCE}

Adley CC, Saieb FM. 2005. Comparison of biomeriueux API 20NE and Remel RapiD NF Plus, identification systems of type strains of Ralstonia pickettii. Lett Appl Microbiol 41 (2): 136-140. DOI: 10.1111/j.1472-765X.2005.01737.x.

Austin B, Austin DA. 2007. Bacterial Fish Pathogens: Diseases of Farmed and Wild Fish, 4th ed. Praxis Publishing Ltd, United Kingdom.

Bernardet JF, Hugo C, Bruun B. 2006. The Genera Chryseobacterium and Elizabethkingia the Prokaryotes: A Handbook on The Biology of Bacteria, 3rd edition. Springer 638-76. DOI: 10.1007/0-387-30747-8_25.

Bernardet JF, Segers P, Vancanneyt M, Berthe F, Kersters K, Vandamme P. 1996. Cutting a Gordian knot: Amended classification and description of the genus Flavobacterium, amended description of the family Flavobacteriaceae, and proposal of Flavobacterium hydatis nom. nov. Intl J Syst Bacteriol 46 (1): 128-148. DOI: 10.1099/00207713-46-1-128.

Chinabut S, Somsiri T, Danayadol. 2002. Impacts of disease in smallscale aquaculture in Thailand: case studies, Primary Aquatic Animal Health Care in Rural, Small-scale, Aquaculture Development. FAO Fisheries Technical Paper.
Chinnarajan R, Govindaswamy RV, Rajasabapathy R, LogeshwaranV, Sreepada RA. 2015. Infection and pathogenecity of Myroides odoratimimus (NIOCR-12) isolated from the gut of grey mullet (Mugil cephalus Linnaeus, (1758)). J Microbiol 88: 22-28. DOI: 10.1016/j.micpath.2015.08.001.

Farmer B. 2004. Improved Methods for the Isolation and Characterization of Flavobacterium columnare. [Dissertation]. Louisiana State University, Agricultural and Mechanical College, Baton Rouge, LA.

Felsenstein J. 1985. Confidence limits on phylogenies: An approach using the bootstrap. Evol 39 (4): 783-791. DOI: 10.1111/j.1558-5646.1985.tb00420.x.

Kimura M. 1980. A simple method for estimating evolutionary rate of base substitutions through comparative studies of nucleotide sequences. J Mol Evol 16 (2): 111-120. DOI: 10.1007/BF01731581.

Kumar S, Stecher G, Tamura K. 2016. MEGA7: Molecular Evolutionary Genetics Analysis version 7.0 for bigger datasets. Mol Biol Evol 33 (7): 1870-1874. DOI: 10.1093/molbev/msw054.

Lee SH, Kim JM, Lee JR, Park W, Jean CO. 2010. Flavobacterium fluviin sp. nov., isolated from stream sediment. Int J Sys Evol Microbiol 60 (2): 353-357. DOI: 10.1099/ijs.0.010850-0.

Loch PT, Faisal M. 2015. Emerging Flavobacterial infections in fish: A review. J Adv Res 6 (3): 283-300. DOI: 10.1016/j.jare.2014.10.009.

Loch PT. 2014. Identification of Novel Flavobacteria from Michigan and Assessment of Their Impacts on Fish Health. Michigan State Univ., USA.

Loch T, Faisal M. 2014. Chryseobacterium aahli sp. nov., isolated from lake trout (Salvelinus namaycush) and brown trout (Salmo trutta), and emended descriptions of Chryseobacterium ginsenosidimutans and Chryseobacterium gregarium. Intl J Syst Evol Microbiolol 64 (5): 1573-1579. DOI: 10.1099/ijs.0.052373-0.

MAAIF [Ministry of Agriculture Animal Industry and Fisheries]. 2004. The National Fisheries Policy. 1st edition. Department of Fishery Resources. Kampala, Uganda.

Nematollahi A, Decostere A, Pasmans F, Haesebrouck F. 2003. Flavobacterium psychrophilum infections in salmonid fish. J Fish Dis 26 (10): 563-74. DOI: 10.1046/j.1365-2761.2003.00488.x.

Qu JH, Yuan HL, Li HF, Deng CP. 2009. Flavobacterium cauense sp. Nov., isolated from sediment of eutrophic lake. Intl J Sys Evol Microbiol 59 (11): 2666-2669. DOI: 10.1099/ijs.0.009688-0.

Saitou N, Nei M. 1987. The neighbor-joining method-a new method for reconstructing phylogenetic trees. Mol Biol Evol 4 (4): 406-425. DOI: 10.1093/oxfordjournals.molbev.a040454.

Sebastião FA, Pilarski F, Lemos MVF. 2010. Isolation and molecular characterization of Flavobacterium columnare strains from fish in Brazil. J Bacteriol Res 2 (3): 22-29.

Shotts E, Starliper C. 1999. Flavobacterial diseases: columnaris disease, cold-water disease, and bacterial gill disease (Fish diseases and disorders: viral, bacterial, and fungal infections). CABI Publishing; New York (NY) 3: 559- 576.

Starliper CE. 2011. Bacterial coldwater disease of fishes caused by Flavobacterium psychrophilum. J Adv Res 2 (2): 97- 108. DOI: 10.1016/j.jare.2010.04.001

Varga Z, Sellyei B, Paulus P, Papp M, Molnár K, Székely C. 2016. Isolation and characterization of Flavobacteria from wild and cultured freshwater fish species in Hungary. Acta Vet Hung 64 (1): 13- 25. DOI: 10.1556/004.2016.002.

Wagner BA, Wise DJ, Khoo LH, Terhune JS. 2002. The epidemiology of bacterial diseases in food-size channel catfish. J Aquat Anim Health 14 (4): 263-272. DOI: 10.1577/1548-8667(2002)014<0263:TEOBDI >2.0.CO;2.

Wakabayashi H, Huh G, Kimura N. 1989. Flavobacterium branchiophila sp. nov., a causative agent of bacterial gill disease of freshwater fishes. Intl J Sys Bacteriol 39 (3): 213-216. DOI: 10.1099/00207713-39-3-213.

Walakira J, Akoll P, Engole M, Sserwadda M, Nkambo M, Namulawa V, Kityo G, Musimbi F, Abaho I, Kasigwa H, Mbabazi D, Kahwa D, Naigaga I, Birungi D, Rutaisire J, Majalija S. 2014. Common fish diseases and parasites affecting wild and farmed Tilapia and catfish in Central and Western Uganda. Uganda J Agric Sci 15 (2): 113 - 125.

Welker LT, Shoemaker AC, Arias RC, Klesius HP. 2005. Transmission and detection of Flavobacterium columnare in channel catfish Ictalurus punctatus. Dis Aquat Org 63 (2-3): 129-138. DOI: 10.3354/dao063129.

Yoon JH, Park S, Kang SJ, Myung SC, Kim W. 2011. Flavobacterium ponti sp. nov., isolated from seawater. Int J Sys Evol Microbiol 61 (1): 81-85. DOI: 10.1099/ijs.0.017582-0.

Zamora L, Fernández-Garayzábal J, Palacios M, Sánchez-Porro C, SvenssonStadler L, Domínguez L. 2012. Chryseobacterium oncorhynchi sp. nov., isolated from rainbow trout (Oncorhynchus mykiss). Syst Appl Microbiol 35 (1): 24-29. DOI: 10.1016/j.syapm.2011.10.002.

Zamora L, Vela AI, Palacios MA, Sánchez-Porro C, Svensson-Stadler LA, Domínguez L. 2012. Chryseobacterium viscerum sp. nov., isolated from diseased fish. Int J Syst Evol Microbiol 62 (12): 2934-2940. DOI: 10.1099/ijs.0.036699-0. 